\title{
Impact Assessment on an Invasive Species, Lantana camara on Indigenous Species Composition and Socio-economic Environment around Adama and Bishofitu Areas, Ethiopia
}

\author{
Melkamu Kifetew* $\quad$ Prof. Zerihun Woldu \\ Addis Ababa University School of Graduate Studies, Environmental Science Program, PO box 1176, \\ Addis Ababa, Ethiopia
}

The research is financed by Addis Ababa University School of Post Graduate Studies

Abstract

Impact assessment of Lantana camara L. on indigenous species composition and socioeconomic environment was carried around Aroge Adama, Soloqe and Bishfitu areas, Ethiopia. Fifty-four $5 \mathrm{~m}$ x $5 \mathrm{~m}$ releve's were systematically sampled across 3 main transects laid $50 \mathrm{~m}$ from the left side of the main road. In order to reduce the effects of human interference, the sites selected were, as much as possible, far away from the mainroad.There leve's were equally distributed for the three study sites. In each site equal number of releve's with \& without Lantana camara were sampled from the same habitat types. All indigenous species in all non-invaded and along with Lantana camara in all invaded releve's were counted, identified \& recorded. Diversity \& richness was analyzed using Shannon-Weiner species diversity \& richness index. Herbivory was found to be the most prevalent form of disturbance. ANOVA results at $p<0.05$ level of sig. showed that levels of disturbances were variable but are higher in the invaded releve's as compared to the non-invaded releve's. Independent sample t-test \& one-way ANOVA showed significance difference at $\mathrm{p}<0.05$ level. To asses invasion impact Spearman correlation coefficient was calculated for altitude, disturbance, density of Lantana and diversity of native plants. Disturbance and density of Lantana were highly correlated to diversity of native plants. ANOVA results showed significance difference in disturbance, density of Lantana and altitude in invaded releve's and only disturbance showed insignificance difference in the non-invaded releve's. The study revealed disturbance as the major factor, which facilitated the invasion of Lantana camara. Different respondents have different views on its introduction \& current status. Fifty six percent of them agree with its deliberate while $44 \%$ with its accidental introduction. Seventy-four percent of the key informants admitted the benefits obtained from it even though they maintained the disadvantage outweighs its advantages. Thirty seven percent of the key informants responded as there are methods to minimize the detrimental effects \& use it to improve biophysical \& socio economic condition of the areas.

Keywords: Lantana camara, Invasive species, Indigenous species, invaded.

DOI: $10.7176 / \mathrm{JEES} / 11-3-04$

Publication date:March $31^{\text {st }} 2021$

\section{Introduction}

The invasion of habitats by exotic species is a global phenomenon with ecological, economic and social consequences. This issue is expressed in published literature on invasive species such as Williamson (1999); McNeely (2000); Wittenberg et al., (2000); McNeely (2001), among others. (The 1996 UN conference on invasive species ranked these species second only to habitat destruction as a threat to species and biodiversity loss (UNEP, 2000b, 2000c; Katerina et al., 2004).

It is reported that the attributes of successful invaders, and the characteristics that make a community prone to invasion, are poorly understood and a global explanation for invasiveness may simply not exist. However (D'Antonio, 2000; Hobbs, 2000), life history traits that promote establishment of populations after disturbance, such as rapid germination and initial growth to be the means for the success of invasive species.

The attributes of a community in which species are introduced are important in determining the outcome of an invasion. Segrtain et al., (2004) and Annon, (2003) claim the outcome of an invasion to be influenced by both abiotic factors such as type and frequency of disturbance and biotic characteristics such as the abundance of natural enemies, competition and mutualism in the host community and propagule supply.

Williamson (1996), stated that non-indigenous species interact with indigenous species as well as previously established non-indigenous species. These interactions and abiotic factors determine the establishment success of new species. McNeely (2000), wrote that altered competitive interactions are one possible ecological consequence of invasive species by which they outcompete native species.

Non-indigenous species come from somewhere else and are not natural to the ecosystem they have been introduced. Cronk et al. (1995), stated that they may be harmless and beneficial in their natural surroundings, but where there are no established natural controls such as natural predators to keep the non-native harmful species in check, there can be a population explosion of the non-native invasive species causing an ecological catastrophe. They can disrupt natural balance, reduce biodiversity, and alternative genetic diversity, transmit exotic genetic 
diseases to native species, and further jeopardize endangered plants and animals.

The simplification of ecological communities might make them more vulnerable to invasion or render them less stable or predictable inspecies composition.Inextremecases, invasive species may also reduce nature species richness that the original natural community no longer exists (McNeely, 2001; Mack et al., 1998).

Studies indicate that Lantana camara L. is one of the invasive species, which is native to tropical America, and is now found in most tropical and sub-tropical regions of the world including Ethiopia. It has been declared noxious weed as it is detrimental to many human activities (e.g. Agriculture, Tourism) as well as a threat to natural ecosystems (Takur et al, 1992; Dessalegn, 2003; EARO). Lantana tolerates a wide range of climates and is found anywhere between sea level and $1000 \mathrm{~m}$ asl and in places even at higher altitudes, but is limited by frost (Gentle and Duggin, 1997). It can grow in high rainfall areas with tropical sub-tropical and temperate climates. It doesn't tolerate salty or dry soils, water logging or low temperature $\left(<5^{0} \mathrm{c}\right)$. It thrives on rich, organic soils but also grows on well-drained clay and basalt soils. Sandy soils tend to dry out too rapidly for Lantana unless soil moisture is continually replenished. In the study areas Lantana is given the local name "Yewef Kollo" (Probably because it is mostly dispersed by birds). And "Tikure" (May be because the seeds turn dark upon maturity).

Currently Lantana is rapidly invading agricultural and grazing areas; and has encroached hundreds of kms from its initial areas along the roadsides of the study areas (local people, personal communication). As a result of its rampant invasion it has become the cause of discussion among farmers, development agencies, scientists and policy makers. The farmers and concerned government bodies are looking for knowledge/experience/technologies that can assist in either controlling or eradication of the species.

The Environmental Policy of Ethiopia (EPE) and the National Biodiversity Strategy and Action Plan (NBSAP) have identified invasive species as posing a major threat to biodiversity and economic well-being of the population. However, little attempt to assess the status of invasive alien species (IAS) has been made; so those species known to be threats are those that are already wide spread Ethiopian Agricultural Research Organization (EARO).Attempts to combat the threat of invasives in Ethiopia have followed the usual piecemeal approach, they have not been coordinated across sectors, and have focused mainly on attempting to address the major invaders. The emphasis is on tackling problems that threaten agriculture and human activity, there being insufficient resources, capacity or information available to address the threats to natural ecosystems.

Under the Ethiopian Agricultural Research Organization (EARO), as an executing agency there is a project with a goal to protect ecosystem, species, and genetic diversity from invasive alien species, for global, national and community benefit. The project will contribute to this goal through its purpose of removing the barriers to effective prevention and management of IAS in four pilot countries; Ethiopia, Ghana, Uganda and Zambia. The focus will be on invasive plants, as this group poses the greatest current threat, and because a number of invasive plant species of both terrestrial and aquatic ecosystems have been identified in the four countries requiring immediate attention.

Therefore, the need to study the impact of Lantana on the selected areas is essential for the management of biodiversity, monitoring of the existing situation and to evaluate the current status of the species. Furthermore, this study will contribute to the decision on the conservation, use and management of plant biodiversity in the region.

The analysis of socioeconomic impact of Lantana will also contribute to the environmental measures taken by environmentalists, ecologists, ethno botanists, and range managers in the region. In addition, the result of the study will also be used in the strategic actions to participate the local community in the management and control measures of this alien species with environmentally friendly actions and actions which consider cost-benefit analysis and in relation to the surrounding plant biodiversity in the region.

\section{Material and Methods}

2.1. Description of Study Area

The town of Adama is found in the Ethiopian rift valley, about $90 \mathrm{kms}$, South East of Addis Ababa, the capital. It is located at $8^{0} 30^{\prime} \mathrm{N}$ latitude and $39^{\circ} 12^{\prime} \mathrm{E}$ longitudes at an average altitude of $1600 \mathrm{~m}$ (range1550-1600).It has a typical arid climate.

The soils range from sandy to loamy and are intensively cultivated. The area grows teff, maize, millet, etc., and is also favourable for growing vegetables and fruits like onion, potato, orange, papaya, grapes and the like. With respect to vegetation, spiny-leaved plants, dominated by Acacia, typical of arid areas, characterize the region. The mean annual temperature and rainfall of Adama is $20.194^{\circ} \mathrm{C}$ and $741.43 \mathrm{~mm}$ respectively. Its mean maximum temperature reaches $30.8^{\circ} \mathrm{C}$ in May, whereas the mean minimum temperature is $12^{\circ} \mathrm{C}$ in December. Its wettest season is between July $(219.282 \mathrm{~mm})$ and September $(104.455 \mathrm{~mm})$ of rainfall, but the mean maximum and minimum rainfall are $223.45 \mathrm{~mm}$ and $13.8 \mathrm{~mm}$ in August and February respectively.

Bishofitu lies at latitude $8^{0} 44^{\prime} \mathrm{N}$ and longitude $38^{\circ} 58^{\prime} \mathrm{E}$, with an average altitude of $1,850 \mathrm{masl}$. The town is located on the escarpment of the Great Rift Valley. The lakes and the position of the town on the escarpment of the great valley, has influence on the climate of the area. The mean annual temperature and rainfall of Bisihofitu is $18.8^{\circ} \mathrm{C}$ and $711.84 \mathrm{~mm}$ respectively. Its mean maximum temperature reaches $29.5^{\circ} \mathrm{C}$ in May whereas the mean 
minimum temperature is $9^{0} \mathrm{C}$ in January. The wettest season of Bisihofitu is between June $(115.22 \mathrm{~mm})$ and August $(214.47 \mathrm{~mm})$ of rainfall but the mean maximum and minimum rainfall are $226.99 \mathrm{~mm}$ and $12.36 \mathrm{~mm}$ in July and November respectively.

The town of Adama is situated in a basin like flat land surrounded by ridges and hills in the west, south and east. There is no permanent river, which endangers settlement in the town. However its basin like position discourages the peripheral areas of the town for settlement due to the flood generated from the hills and ridges. In spite of the presence of channels to discharge water, most areas along the north western ridge are not favoured for settlement because of the presence of direct run off. Flood from the southern ridge and south eastern hills gathered in the south eastern depression create swamp, which become mosquito breeding sites. The topography of Bishofitu area is greatly altered by the geologic formation of crater lakes.

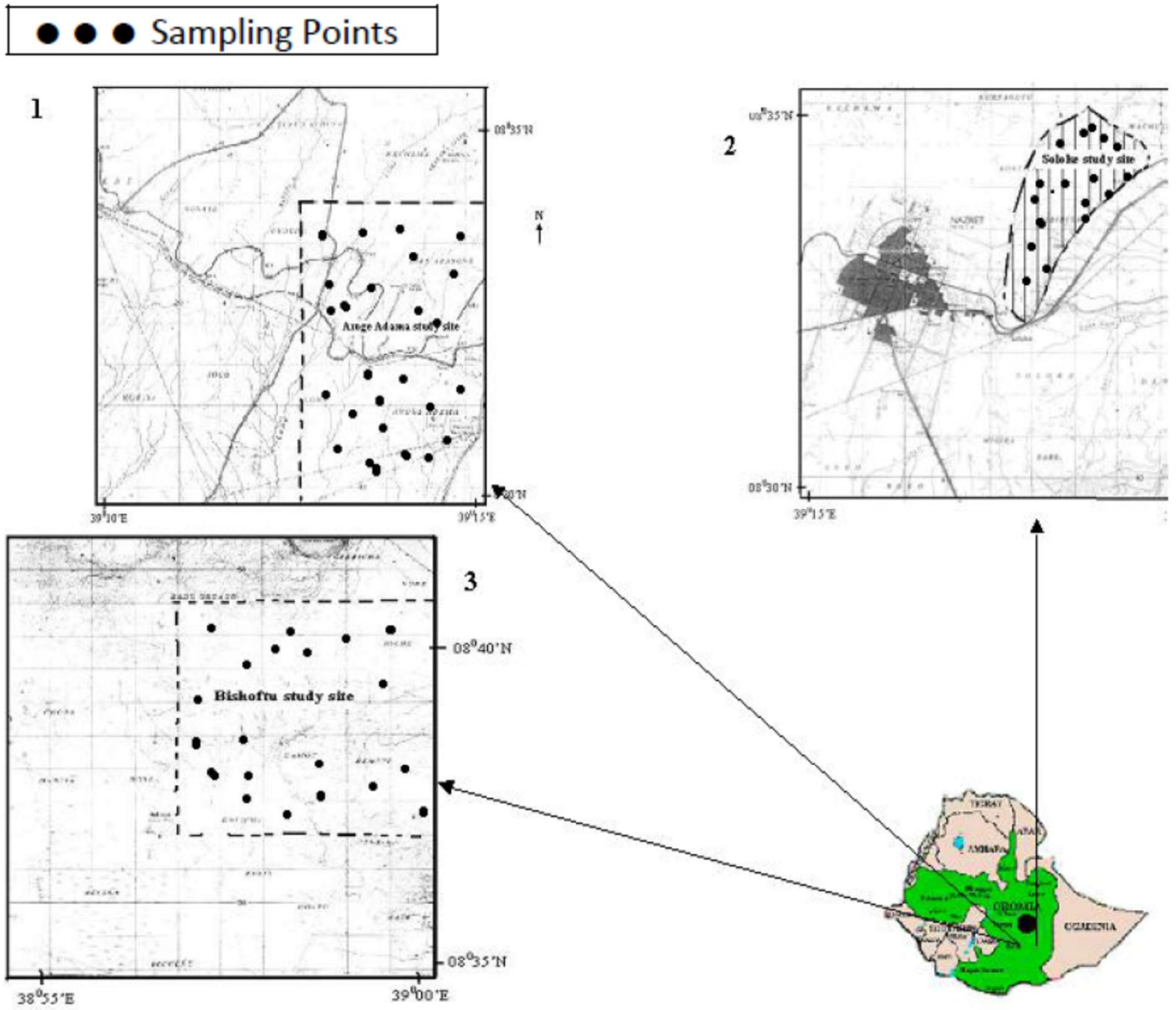

Fig 1 Map of the Study Sites: (1). Aroge Adama (2). Soloqe (3). Bishofitu

Source Ethiopian Mapping Authority.

\subsection{Data Collection}

\subsubsection{Biophysical Data Sampling}

Fifty-four $5 \mathrm{~m}$ x $5 \mathrm{~m}$ plots were systematically established based on homogeneity and representativeness in the study areas. The number of plots were distributed equally for the three study sites; Aroge adama, Soloqe, and Bisihoftu. Quadrats were laid across three transects laid $50 \mathrm{~m}$ from the left side of the main road. In order to reduce the effects of human interference, the sites selected were, as much as possible, far away from the main road and human settlement.

Wittenberg et al., (2000), suggested that pairing data has the theoretical effect of reducing measurement variability (i.e. variance), which increases the accuracy of statistical conclusion. More over two treatments should be laid side by side in the field in order to avoid unnecessary differences in soil, moisture, temperature, etc. Two plots next to each other usually respond more alike than those at a distance. Non-invaded sample plots should be 
chosen as close as possible to invaded plots to represent primary communities where invasions have taken place (Pimentel et al., 2000). If the habitats were not identical the assessment may partly introduce different habitat parameters (i.e. the invasive may not be growing in some of the plots due to variation in certain characteristics).Considering the suggestions given, in the three study sites invaded patches and surrounding Lantana free vegetations in the same habitat type were sampled as releve' pairs. The releve' pairs chosen have the same plot size.

Individuals of each plant species in each releve's (quadrat) with $5 \mathrm{mx} 5 \mathrm{~m}$ were counted. Individuals having their canopy with in the plots and that were rooted outside were not included in the count. Plant specimens in each plot were collected and pressed for identification at the National herbarium of the Addis Ababa University; vernacular names were recorded in the field.

Altitude and GPS records were taken for the 54 releve's using GPS. Disturbance were recorded as reflected by the actual presence of animals, their trails and droppings, the removal of plant material and soil due to animal grazing, browsing and movement among others.

The levels of disturbance recorded were assessed using a subjective scale of 0-3, detailed as follows: (0)nil ; (1)-low ; (2)-moderate ;(3)-heavy (Kumilachew and Taye, 2003).

2.2.2 Socioeconomic Data

Socio-economic information on condition of introduction, status, use value and impact, and management (means to reduce its adverse impacts and methods to make the species beneficial) and attitude data were collected using semi-structured interview. A total of 54 key informants were interviewed. All of them are farmers.

\subsection{Data Analysis}

2.3.1 Biophysical Data Analysis

The indigenous species in the sample pairs; in the invaded and non-invaded releve's were compared using Shannon diversity index to investigate the variation in species diversity and richness (determined using Shannon diversity index) and t-test.

The diversity and richness of species in the three study sites was determined using Fortran Computer Program for Shannon-Weiner index.

ANOVA is used for the analysis of the variation in species diversity in the invaded and non-invaded releve's in all the study sites.

To establish the level by which the diversity and abundance/density of indigenous species were vulnerable to invasion, Spearman's rank correlation coefficients, rs (rho), for altitude, disturbance, and density of Lantana were determined

2.3.2 Socioeconomic Data Analysis

The data collected using semi-structured interviews on 54 key informants on the introduction, use value, impact and management (means to reduce its adverse impact) and attitude towards it was analysed using SPSS program.

\section{Results}

3.1 Species Diversity

Table1 Shannon-Weiner diversity and species richness values for the three study sites

\begin{tabular}{|l|c|l|c|}
\hline & Site1(ArogeAdama) & Site 2(Soloqe) & Site3 (Bishofitu) \\
\hline Spp.diversity $\left(\mathrm{H}^{\prime}\right)$ & 2.79 & 3.14 & 2.74 \\
\hline Spp. richness $(\mathrm{N})$ & 24 & 31 & 20 \\
\hline
\end{tabular}

Table 2. Shannon -Weiner diversity values for Invaded and Non- invaded releve's for the three study sites

\begin{tabular}{|l|l|l|l|l|l|l|}
\hline \multirow{2}{*}{} & \multicolumn{5}{|c|}{ Sites } \\
\cline { 2 - 7 } & \multicolumn{2}{|c|}{ 1(Aroge Adama) } & \multicolumn{2}{c|}{ 2(Soloqe) } & \multicolumn{2}{c|}{ 3(Bishofitu) } \\
\cline { 2 - 7 } & $\begin{array}{l}\text { Invade } \\
\text { d }\end{array}$ & Non-inv & Invaded & Non-inv & Invaded & Non-inv \\
\hline Spp. diversity (H') & 2.48 & 2.65 & 2.85 & 2.91 & 1.26 & 1.69 \\
\hline
\end{tabular}

The results of Shannon-Wiener diversity index showed that site 2 (Soloqe) has relatively the highest species 
diversity and richness, while site 3 (Bishofitu) has the lowest species diversity and richness site1 (Aroge Adama) being of higher in species diversity and richness. Results of Shannon-Weiner diversity index in invaded and noninvaded plots showed that the vegetation invaded by Lantana has lower species diversity compared to the noninvaded Lantana free vegetation. The independent $\mathrm{t}$-test, comparing the Shannon index in invaded and noninvaded releve's in the three sites showed significance difference (Table3).

Table 3: P-value for independent sample t-test for the three study sites (Site 1: Aroge Adama; Site 2: Soloque; Site3: Bishofitu)

\begin{tabular}{|l|c|c|c|}
\hline & Site 1 & Site 2 & Site 3 \\
\hline P-value & 0.00 & 0.021 & 0.000758 \\
\hline
\end{tabular}

The results of one-way ANOVA test considering H' in the invaded plots (Pvalue: 0.004) and non-invaded plots (Pvalue: 0.000 ) in the three sites showed significant difference in species diversity in the three invaded sites

\subsection{Sources of Disturbance}

All the plots sampled were trampled. Grazing occurred in 24 plots, 17 plots were browsed. While the combined effects of browsing and grazing occurred in 9 plots. Stone removal occurred in 4 invaded releve's of Bishofitu.

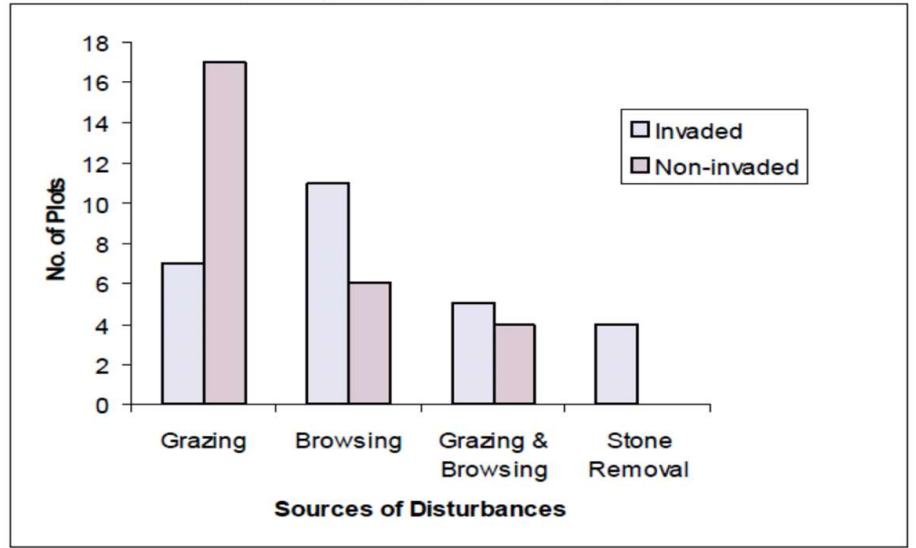

Fig.3 Sources of Disturbances in the Plots Sampled in Invaded and Non-invaded releve's in all the three Study Sites

\subsection{Levels of Disturbance}

All the plots sampled were disturbed. In the invaded areas 15 plots were highly disturbed, 8 moderately and low level of disturbance affected 4 plots. In the non-invaded areas 4 plots were highly disturbed,14 moderately and 4 at low level.

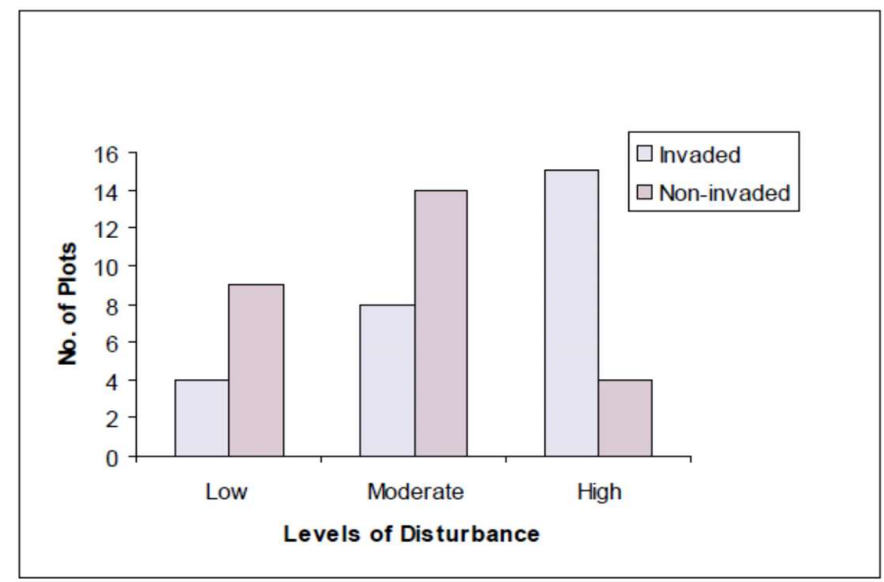

Fig 4. Levels of Disturbances in all the Plots Sampled in Invaded and Non-invaded releve's 
(a)
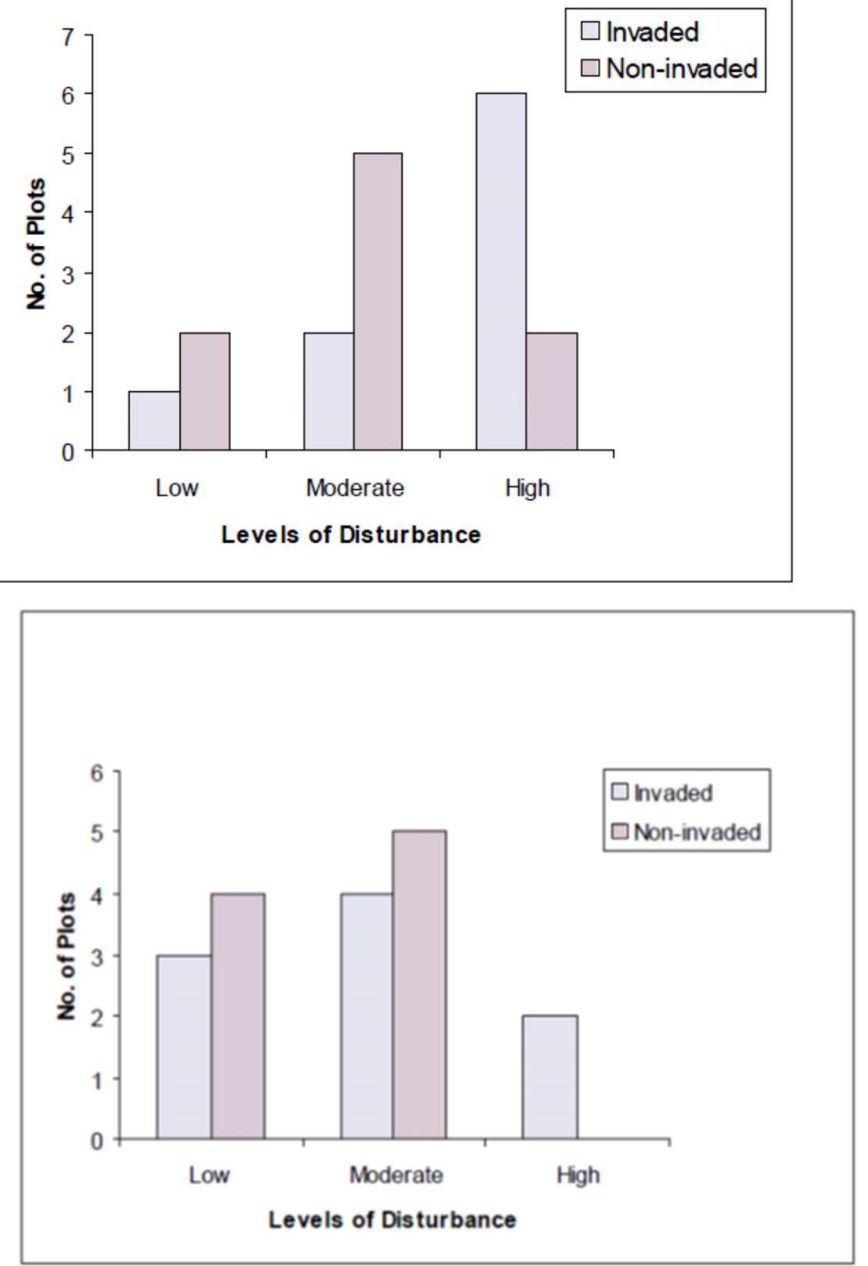

(b)

(c)

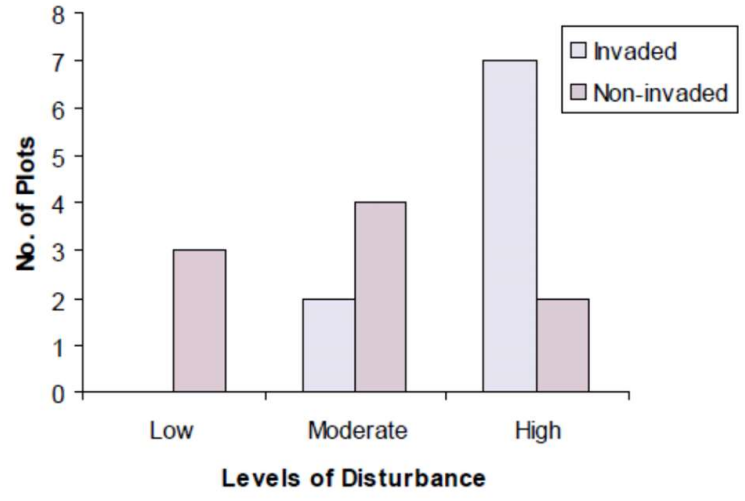

Fig.5 Levels of Disturbance (Invaded and Non-invaded) releve's in (a) Aroge Adama (b)Soloque (c)Bishofitu 
Types and levels of disturbances were variable for all the sites. Out of 18 releve's sampled in Aroge Adama; six were highly disturbed mainly by browsing and trampling in invaded releve's. In the non-invaded releve's,moderate levels of disturbance were recorded in most plots (Fig5a).

In Soloque (Fig 5b), invaded releve's 2 plots had high level of disturbance. In the non-invaded releve's the disturbance level decreased, 4 releve's had low level of disturbance while 5 moderate.

In Bishofitu (Fig 5c), in the invaded releve's 7 plots had high level of disturbance. In the non-invaded releve's 3 plots had low and 4 moderate level of disturbance.

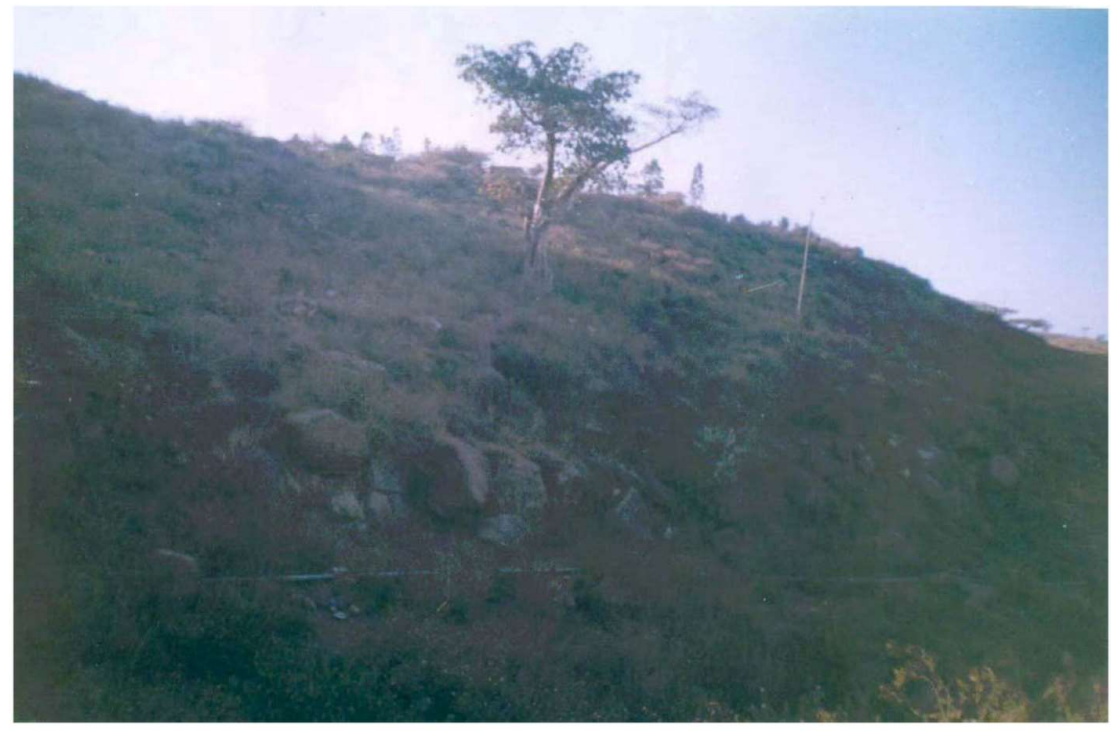

(a)

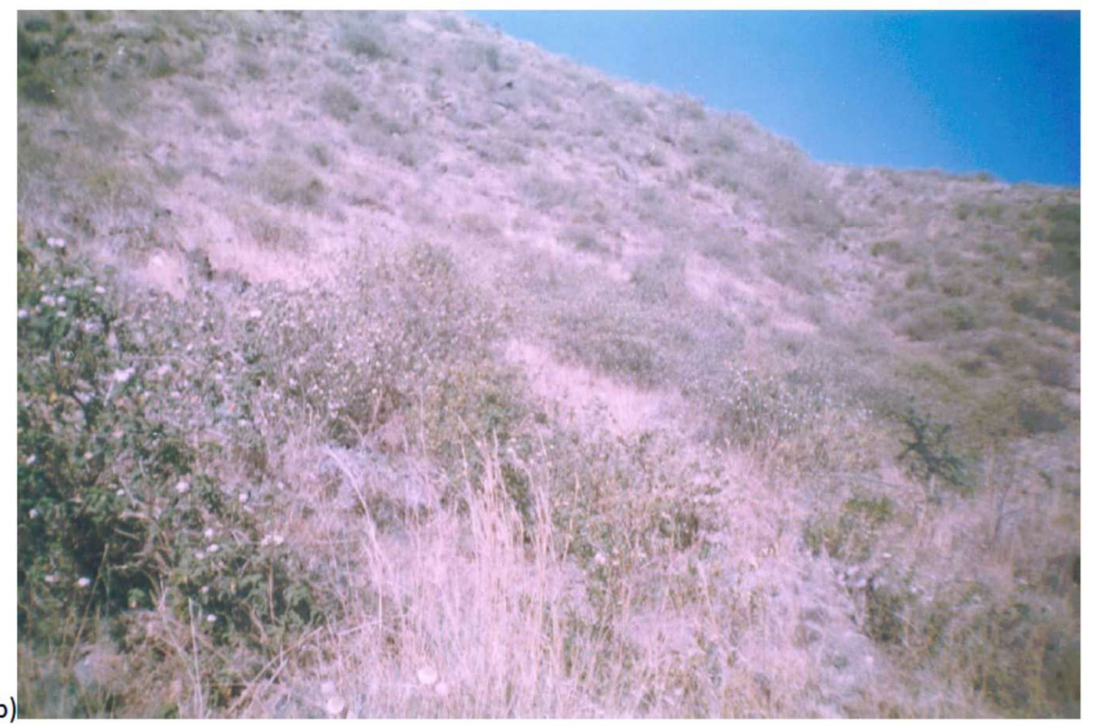

Fig 6.Photos Showing Invaded Patches in (a) Aroge Adama (b) Soloque

3.4 The Relationship between Species Diversity and Environmental Variables

To establish the relationship between diversity of native species and environmental factors spearman rank correlation coefficients rs (rho) were determined.

Table 4 a \& b summarizes the results for Aroge Adama. In the invaded releve's, vegetation diversity is highly negatively correlated with disturbance (r:-0. 839) and density of Lantana (r:-0. 835). While Lantana density and disturbance were highly positively correlated (r: 0.840). In the non-invaded releve's (Table 4b) vegetation diversity is highly negatively correlated with disturbance level (r:-0.948) (at $\mathrm{P} \leq 0.001)$. 
Table 4a Spearman rs (rho) Correlation for the Invaded releve's of Aroge Adama

\begin{tabular}{|c|c|c|c|c|c|c|c|}
\hline & & & Alt. & Dist. lev & $\mathrm{H}^{\prime}$ & D/NPLs & $\mathrm{D} / \mathrm{La}$ \\
\hline \multirow[t]{15}{*}{ Spearman's rho } & \multirow[t]{3}{*}{$\overline{\text { Alt. }}$} & Correlation Coefficient & 1.000 & -.279 & .199 & .113 & -.159 \\
\hline & & Sig. (2-tailed) & . & .467 & .607 & .772 & .683 \\
\hline & & $\mathrm{N}$ & 9 & 9 & 9 & 9 & 9 \\
\hline & \multirow[t]{3}{*}{ Dist. lev } & Correlation Coefficient & -.279 & 1.000 & $-.839 * *$ & .052 & $.840 *$ \\
\hline & & Sig. (2-tailed) & .467 & . & .005 & .894 & .005 \\
\hline & & $\mathrm{N}$ & 9 & 9 & 9 & 9 & 9 \\
\hline & \multirow[t]{3}{*}{$\mathrm{H}^{\prime}$} & Correlation Coefficient & .199 & $-.839^{\star \star *}$ & 1.000 & .005 & $-.835^{*}$ \\
\hline & & Sig. (2-tailed) & .607 & .005 & . & .991 & .005 \\
\hline & & $\mathrm{N}$ & 9 & 9 & 9 & 9 & 9 \\
\hline & \multirow[t]{3}{*}{ D/NPLs } & Correlation Coefficient & .113 & .052 & .005 & 1.000 & .315 \\
\hline & & Sig. (2-tailed) & .772 & .894 & .991 & . & .410 \\
\hline & & $\mathrm{N}$ & 9 & 9 & 9 & 9 & 9 \\
\hline & \multirow[t]{3}{*}{$\mathrm{D} / \mathrm{La}$} & Correlation Coefficient & -.159 & $.840^{* \star}$ & $-.835^{* *}$ & .315 & 1.000 \\
\hline & & Sig. (2-tailed) & .683 & .005 & .005 & .410 & . \\
\hline & & $\mathrm{N}$ & 9 & 9 & 9 & 9 & 9 \\
\hline
\end{tabular}

**Alt.: Altitude in meters; Dist. lev: disturbance level; H': Shannon-Weiner diversity index D/NPLs: Density of native plants; D/La: Density of Lantana

Table 4b Spearman Correlation rs(rho) for Non-invade releve's of Aroge Adama

\begin{tabular}{|lll|r|r|r|r|}
\hline & & \multicolumn{1}{|c|}{ Alt. } & Dist. lev & \multicolumn{1}{c|}{ H' $^{\prime}$} & \multicolumn{1}{c|}{ D/NPLs } \\
\hline Spearman's rho & Alt. & Correlation Coefficient & 1.000 & -.292 & .162 & .352 \\
& & Sig. (2-tailed) &. & .446 & .676 & .353 \\
& & 9 & 9 & 9 & 9 \\
\cline { 2 - 6 } & Dist. lev & Correlation Coefficient & -.292 & 1.000 & $-.948^{* *}$ & .034 \\
& Sig. (2-tailed) & .446 &. & .000 & .930 \\
& $\mathrm{~N}$ & 9 & 9 & 9 & 9 \\
\hline & Correlation Coefficient & .162 & $-.948^{* *}$ & 1.000 & -.056 \\
& Sig. (2-tailed) & .676 & .000 &. & .887 \\
& $\mathrm{~N}$ & 9 & 9 & 9 & 9 \\
& & .352 & .034 & -.056 & 1.000 \\
& D/NPLs & Correlation Coefficient & .353 & .930 & .887 &. \\
& Sig. (2-tailed) & 9 & 9 & 9 & 9 \\
\hline
\end{tabular}

**Correlation is significant at the .01 level (2-tailed).

In Soloqe invaded releve's (Table 5a), vegetation diversity is highly negatively correlated with disturbance (r:-0. 977) and density of Lantana (r:-0. 950). While Lantana density and disturbance were highly positively correlated (r: 0. 943). In the non-invaded releve's diversity is highly negatively correlated with disturbance(r:$0.968)($ at $\mathrm{P}<0.01)$

Table5a Spearman correlation rs (rho) for non-invade releve's of Soloque

\begin{tabular}{|c|c|c|c|c|c|c|c|}
\hline & & & Alt. & Dist. lev & $\mathrm{H}^{\prime}$ & D/NPLS & $\mathrm{D} / \mathrm{La}$ \\
\hline \multirow[t]{15}{*}{ Spearman's rho } & \multirow[t]{3}{*}{$\overline{\text { Alt. }}$} & Correlation Coefficient & 1.000 & .036 & -.120 & -.518 & .094 \\
\hline & & Sig. (2-tailed) & . & .926 & .758 & .153 & .809 \\
\hline & & $\mathrm{N}$ & 9 & 9 & 9 & 9 & 9 \\
\hline & \multirow[t]{3}{*}{ Dist. lev } & Correlation Coefficient & .036 & 1.000 & $-.977^{\star \star *}$ & .088 & $.943^{*}$ \\
\hline & & Sig. (2-tailed) & .926 & . & .000 & .822 & .000 \\
\hline & & $\mathrm{N}$ & 9 & 9 & 9 & 9 & 9 \\
\hline & \multirow[t]{3}{*}{$\mathrm{H}^{\prime}$} & Correlation Coefficient & -.120 & $-.977^{\star \star}$ & 1.000 & .005 & $-.957^{\star}$ \\
\hline & & Sig. (2-tailed) & .758 & .000 & . & .991 & .000 \\
\hline & & $\mathrm{N}$ & 9 & 9 & 9 & 9 & 9 \\
\hline & \multirow[t]{3}{*}{ D/NPLs } & Correlation Coefficient & -.518 & .088 & .005 & 1.000 & -.109 \\
\hline & & Sig. (2-tailed) & .153 & .822 & .991 & . & .780 \\
\hline & & $\mathrm{N}$ & 9 & 9 & 9 & 9 & 9 \\
\hline & \multirow[t]{3}{*}{$\mathrm{D} / \mathrm{La}$} & Correlation Coefficient & .094 & $.943^{\star *}$ & $-.957^{\star \star *}$ & -.109 & 1.000 \\
\hline & & Sig. (2-tailed) & .809 & .000 & .000 & .780 & 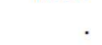 \\
\hline & & $\mathrm{N}$ & 9 & 9 & 9 & 9 & 9 \\
\hline
\end{tabular}

** Correlation is significant at the .01 level (2-tailed). 
Table 5b Spearman Correlation rs (rho) for Non-invade releve's of Soloque

\begin{tabular}{|c|c|c|c|c|c|c|}
\hline & & & Alt. & Dist. lev & $\mathrm{H}^{\prime}$ & D/NPLs \\
\hline \multirow[t]{12}{*}{ Spearman's rho } & \multirow[t]{3}{*}{ Alt. } & Correlation Coefficient & 1.000 & -.174 & .299 & -.018 \\
\hline & & Sig. (2-tailed) & . & .654 & .434 & .964 \\
\hline & & $\mathrm{N}$ & 9 & 9 & 9 & 9 \\
\hline & \multirow[t]{3}{*}{ Dist. lev } & Correlation Coefficient & -.174 & 1.000 & $-.968^{\star *}$ & .045 \\
\hline & & Sig. (2-tailed) & .654 & . & .000 & .908 \\
\hline & & $\mathrm{N}$ & 9 & 9 & 9 & 9 \\
\hline & \multirow[t]{3}{*}{$\mathrm{H}^{\prime}$} & Correlation Coefficient & .299 & $-.968^{* \star}$ & 1.000 & .117 \\
\hline & & Sig. (2-tailed) & .434 & .000 & . & .764 \\
\hline & & $\mathrm{N}$ & 9 & 9 & 9 & 9 \\
\hline & \multirow[t]{3}{*}{ D/NPLs } & Correlation Coefficient & -.018 & .045 & .117 & 1.000 \\
\hline & & Sig. (2-tailed) & .964 & .908 & .764 & . \\
\hline & & $\mathrm{N}$ & 9 & 9 & 9 & 9 \\
\hline
\end{tabular}

** Correlation is significant at the .01 level (2-tailed)

In Bisihofitu, in the invaded releve's, (Table 6a), diversity and density of native plants is negatively correlated with disturbance (r:-0.753).Lantana density is positively correlated with disturbance (r: 0.731$)$ and negatively with diversity and density of native plants (r:-0. 734). For the non-invaded releve's (Table 6b), diversity and native plant density is negatively correlated with disturbance (r: 0.787) (at $\mathrm{P} \leq 0.05)$

Table 6a Spearman correlation rs (rho) for invade releve's of Bisihofitu

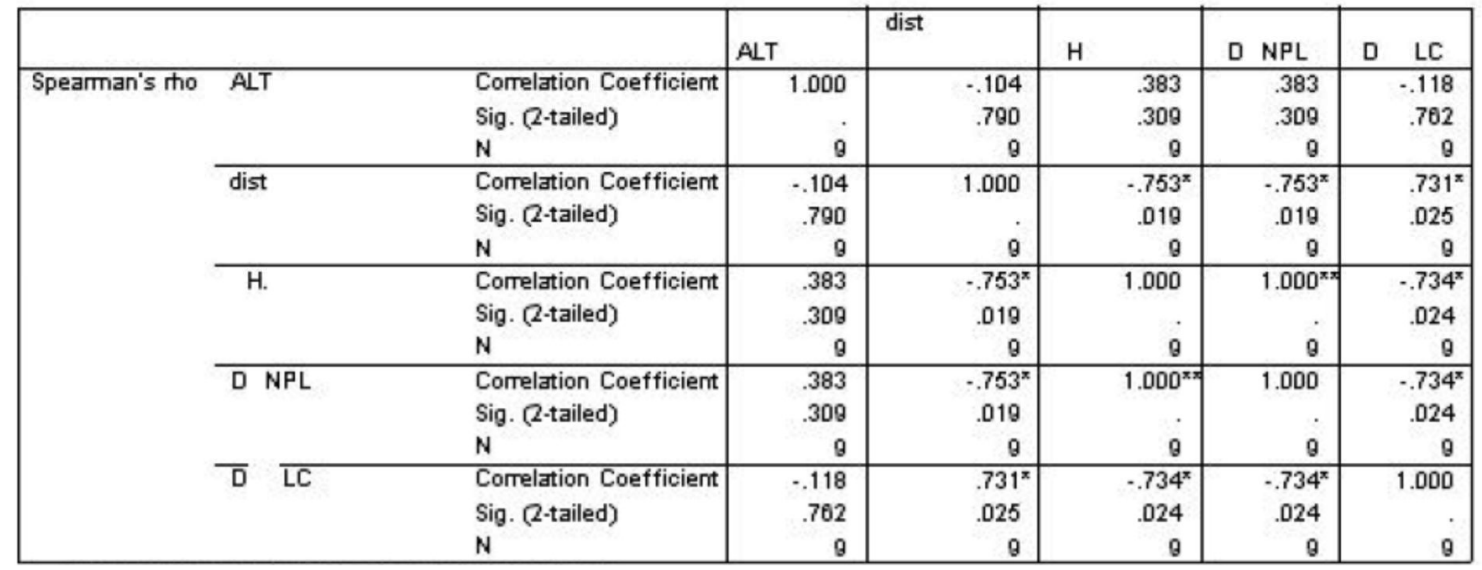

* Correlation is significant at the .05 level (2-tailed)

$* *$ Correlation is significant at the .01 level (2-tailed)

Table $6 \mathrm{~b}$ Spearman Correlation rs (rho) for Non-invade releve's of Bisihofitu

\begin{tabular}{|c|c|c|c|c|c|c|}
\hline & & & Alt. & Dist. lev & $\mathrm{H}^{\prime}$ & D/NPLs \\
\hline \multirow[t]{12}{*}{ Spearman's rho } & \multirow[t]{3}{*}{ Alt. } & Correlation Coefficient & 1.000 & -.267 & .346 & -.267 \\
\hline & & Sig. (2-tailed) & . & .487 & .361 & .487 \\
\hline & & $\mathrm{N}$ & 9 & 9 & 9 & 9 \\
\hline & \multirow[t]{3}{*}{ Dist. lev } & Correlation Coefficient & -.267 & 1.000 & $-.787^{*}$ & $1.000^{*}$ \\
\hline & & Sig. (2-tailed) & .487 & . & .012 & . \\
\hline & & $\mathrm{N}$ & 9 & 9 & 9 & 9 \\
\hline & \multirow[t]{3}{*}{$\mathrm{H}^{\prime}$} & Correlation Coefficient & .346 & $-.787^{\star}$ & 1.000 & $-.787^{\star}$ \\
\hline & & Sig. (2-tailed) & .361 & .012 & . & .012 \\
\hline & & $\mathrm{N}$ & 9 & 9 & 9 & 9 \\
\hline & \multirow[t]{3}{*}{ D/NPLs } & Correlation Coefficient & -.267 & $1.000^{\star *}$ & $-.787^{*}$ & 1.000 \\
\hline & & Sig. (2-tailed) & .487 & . & .012 & . \\
\hline & & $\mathrm{N}$ & 9 & 9 & 9 & 9 \\
\hline
\end{tabular}

* Correlation is significant at the .05 level (2-tailed)

** Correlation is significant at the .01 level (2-tailed) 
Analysis of variance was performed to detect variation in the invaded and non-invaded releve's in the three study sites with respect to disturbance, altitude and density of Lantana. The result showed that in the invaded releve's (Table7a) in the three sites altitude, disturbance and Lantana density showed significant difference at $\mathrm{P} \leq 0.025$. In the non-invaded releve's (Table $7 \mathrm{~b}$ ), altitude showed significant difference while disturbance showed no significant difference (at $\mathrm{P} \leq 0.000$ )

Table 7a ANOVA results of Invaded releve's for Environmental Factors

\begin{tabular}{|c|c|c|c|c|c|c|}
\hline & & $\begin{array}{c}\text { Sum of } \\
\text { Squares }\end{array}$ & $\mathrm{df}$ & Mean Square & $F$ & Sig. \\
\hline \multirow[t]{3}{*}{ ALTITUDE } & Between Groups & 396941.6 & 2 & 198470.778 & 1327.399 & .000 \\
\hline & Within Groups & 3588.444 & 24 & 149.519 & & \\
\hline & Total & 400530.0 & 26 & & & \\
\hline \multirow[t]{3}{*}{ disturbance leve } & Between Groups & 3.852 & 2 & 1.926 & 4.333 & .025 \\
\hline & Within Groups & 10.667 & 24 & .444 & & \\
\hline & Total & 14.519 & 26 & & & \\
\hline \multirow[t]{3}{*}{ SHANNONE } & Between Groups & 1.425 & 2 & .712 & 6.867 & .004 \\
\hline & Within Groups & 2.490 & 24 & .104 & & \\
\hline & Total & 3.915 & 26 & & & \\
\hline \multirow[t]{3}{*}{ DENPL } & Between Groups & 41.407 & 2 & 20.704 & 6.944 & .004 \\
\hline & Within Groups & 71.556 & 24 & 2.981 & & \\
\hline & Total & 112.963 & 26 & & & \\
\hline \multirow[t]{3}{*}{ DENLC } & Between Groups & 1166.519 & 2 & 583.259 & 15.666 & .000 \\
\hline & Within Groups & 893.556 & 24 & 37.231 & & \\
\hline & Total & 2060.074 & 26 & & & \\
\hline
\end{tabular}

Table 7b ANOVA results of Non-invaded releve's for Environmental Factors

\begin{tabular}{|c|c|c|c|c|c|c|}
\hline & & $\begin{array}{c}\text { Sum of } \\
\text { Squares }\end{array}$ & $\mathrm{df}$ & Mean Square & $\mathrm{F}$ & Sig. \\
\hline \multirow[t]{3}{*}{ ALLTITUDE } & Between Groups & 393179.6 & 2 & 196589.815 & 481.586 & .000 \\
\hline & Within Groups & 9797.111 & 24 & 408.213 & & \\
\hline & Total & 402976.7 & 26 & & & \\
\hline \multirow[t]{3}{*}{ disturbance level } & Between Groups & .963 & 2 & .481 & 1.040 & .369 \\
\hline & Within Groups & 11.111 & 24 & .463 & & \\
\hline & Total & 12.074 & 26 & & & \\
\hline \multirow[t]{3}{*}{ SHANNONE } & Between Groups & 1.175 & 2 & .587 & 28.814 & .000 \\
\hline & Within Groups & .489 & 24 & $2.038 \mathrm{E}-02$ & & \\
\hline & Total & 1.664 & 26 & & & \\
\hline \multirow[t]{3}{*}{ DENPL } & Between Groups & 266.000 & 2 & 133.000 & 78.492 & .000 \\
\hline & Within Groups & 40.667 & 24 & 1.694 & & \\
\hline & Total & 306.667 & 26 & & & \\
\hline
\end{tabular}

3.5 Socioeconomic Importance and Impacts

The respondents have different views on the introduction of Lantana and its current status in Ethiopia. About fifty six percent of the respondents agree that it is introduced deliberately as an ornamental plant, while forty four percent of them agree on its accidental introduction. All respondents claim that the species is currently infesting large areas (aided by wind, running water and excretion of animals) and has created problems by displacing indigenous species through competition for resource and shedding. Preventing movement of livestock and humans by forming dense thickets. Serving as host for rats, porcupines and hyenas, which attack their cattle and crops. Encroaches on agricultural land. Decreasing the carrying capacity of pastures. Eighty five percent of the respondents reported seed production as its major means of encroachment.

Hundred percent of the key informants admitted, as there are species which can outcompete it by shedding and competition for resource (for example, Grevillea robusta, Tarenna graveolens, Acacia saligna, Acacia seyal, Asparagus africanus, Acacia nilotica). Eighty three percent of the respondents associate the impact to crop production, through encroachment on farmlands and increasing the labor cost of production. The informants 
reported that in every sowing season they pay considerable amount of money for daily laborers for clearing Lantana from their farmlands.

Livestock production is also affected by the species. Due to its thicket forming nature it inhibits livestock and causes wounding in cattle, goats and sheep. Most of the respondents concluded that the species has more disadvantages than advantages and stressed that they are looking for knowledge/experience/technology that can assist them in either controlling or eradication of the species.

About $26 \%$ of the respondents have the opinion that no benefits are derived from the species while $74 \%$ of the informants admitted that, even if its disadvantage outweigh the advantage, the local people are benefitting from Lantana. Based on the respondents response Lantana can be used to control erosion; increase soil fertility (Sixty percent of the key informants reported that the soil fertility improves after removing Lantana; useful as shedding; fuel wood; medicinal; hedge; food for cattle, monkey, porcupines, rats, birds, etc.

Thirty seven percent of the key informants reported, as there are methods to minimize the detrimental effects of the species and use it in ways that improve biophysical and socioeconomic conditions of the area. Accordingly:

- Allowing it to grow in highly eroded and flood prone areas rehabilitates the areas and decreases the rate and extent of erosion.

- Planting it around farm lands prevents soil erosion of agricultural lands.

- Planting those species of plants, which can compete or destroy it.

- Using it as ornamental and boundary hedge.

- Cultivating the area.

- Use of herbicides.

Even if Lantana offers direct and indirect benefits the attitude of the local people and government and nongovernment organization is negative.

\section{Discussion}

4.1 Impacts of Invasion on Species Diversity

In this study, lower diversity indices were recorded in the non-invaded releve's in all the three sites. According to (Barnes, 1997), invaded and non-invaded communities are distinct. Invaded communities have low diversity because invasive plants alter the invaded ecosystem and species composition to such an extent that they threaten native flora and fauna. Thus, the high value of Shannon-Weiner diversity index in the non-invaded plots/releve's and its significant difference $(\mathrm{P}<0.005)$ in independent t-test in invaded and non-invaded releve's suggests that Lantana has impact on the indigenous species composition through decrease in species diversity. This concurs in many studies conducted in different parts and vegetation types of the world (Binggli \& Dessalegn 2002; Binggli et al., 1998; Morton, 1994; Sharma etal., 1988; Hailu, 2002; Kassahun, 1999; Annon, 2003), which have reported that in natural areas the shrub has series deleterious effect on some endemic animals and plant species and is known to displace natural scrub communities as well as prevent natural regeneration of some tree species. Invasive species utilize soil, water and space of the more desired crops of agriculture, forestry and protected areas. They replace natural vegetation and threaten its natural land scape, upsetting ecosystem composition, process and productivity.

The variation in Shannon-Weiner species diversity index and richness value in the three sites and also oneway ANOVA test for Shannon index in the invaded and non-invaded releve's in the three sites showed significant difference. This may be due to variation in Lantana impact brought by difference in disturbance level. In this study high disturbance level is recorded in sitel (Aroge Adama) and site 3 (Bishofitu) while moderate level in site 2 (Soloqe).Acccording to (Roxana et al., 2003), most invasive species thrive on disturbed sites, they could change its disturbance regime (type, frequency and /or intensity). For example, according to (Drake et al., 1997), most woody invaders (space occupiers) take advantage of disturbance, which over time may develop adverse conditions (vulnerability) that the local plants can't tolerate. These suggests that the relatively low diversity in site 1(Aroge Adama) and site 3(Soloqe) to be due to favorable conditions created by high disturbance for the invasive success. However the relatively high diversity in site 2 (Soloqe) suggests low impact of Lantana due to the moderate level of disturbance. This is in agreement with (Crawely, 1997), moderate level of disturbance prevent dominance of few species in favor of a higher number of potential colonists.

4.2 Relationship between Vegetation Diversity and Environmental Factors

Disturbance is one of the main factors determining patterns of species diversity. The high disturbance levels experienced in the invaded releve's are assumed to bring decrease in diversity of species. Independent t-test revealed significant difference. Hobbs (1989), found that diversity is related to the level of disturbance. When disturbance is frequent and high, species may not have enough time to properly establish themselves. Thus few species can persist or repeatedly colonize after disturbance, which also results in low diversity. According to (Wilkinson, 1999), diversity declines when local extinction of grazing and trampling sensitive species exceeds the establishment of new grazing and trampling tolerant species. In this study in the non-invaded releve's, disturbances are relatively lower; correspondingly, species diversity was high for all sites. 
When disturbance is less intense or less frequent, then a greater number of species are given the opportunity to establish themselves. According to the intermediate disturbance hypothesis (IDH), both high and low levels of disturbances reduce diversity while intermediate levels promote higher diversity. Hobbs (1989), also stated that peak diversity should occur at intermediate frequencies and intensities of disturbances. In this study the high species diversity in site 2 (Soloqe) (Table1) is due to moderate level of disturbance experienced.

4.3 Correlation between Lantana camara Density and Environmental factors

In the study high density of Lantana is recorded in site 1 (Aroge Adama) and site 2 (Bishofitu). Hobbes (1989), found that disturbance enhanced the invasion of exotic species by increasing the availability of limiting resources such as light, water or nutrients. Thus the high level of disturbance in site1 (Aroge Adama) and Site 3 (Bishofitu) and the strong positive correlation between disturbance and density of Lantana suggests suitability of conditions for Lantana

Invasion due to disturbance. This is also in agreement with (Barnes, 1997), ecologically open and disturbed forest sites offer establishment of introduced organisms.

The strong negative correlation between density of the invasive species and diversity suggests the availability of conducive conditions due to high disturbance for the invasive species success in competition. Barnes (1997), found that disturbance selectively destroys biota and initiates changes in mutualistic and competitive relations, among organisms. It also destroys forest organisms and changes Species composition and site conditions (on parental material, soil, and hydrology) through shift in the available resource. Their direct effect, cause ecosystem change of which alteration in species composition is one part.

4.4 Socioeconomic Impacts and Importance

The socioeconomic survey made showed that Lantana has both direct and indirect advantages and disadvantages to the local people. As a result the local people have different opinion about the plant. The majority of respondents (Seventy four percent) admitted the importance of the species, but maintained that disadvantage out-weighs the advantage.

According to some local people there was high rate/extent of erosion in the form of gullies affecting their farmland before the introduction of Lantana to the area but after its introduction the extent and rate of impact of erosion has greatly reduced and the land has become productive. Using Lantana as live fence around their farmlands has reduced the effect of erosion. When they cultivate their land after clearing Lantana the land becomes highly productive. This is in agreement with (Swarbrick et al., 1995), Lantana is used as a facilitator of secondary succession, by providing both the humus and shade necessary for successful germination and seedling establishment. It is capable of reforesting laterite soils in the humid regions of Madagascar. Hailu (2002), found that Prosopis has changed the harsh conditions of micro climates by revegetation of deteriorated lands and fighting toxicity in the Afar region of Ethiopia. Lantana is also useful in providing numerous socioeconomic benefits in Madagascar, domestic hens and, butterflies use it for food (Binggli, 2002).

Despite these facts, the people in the study areas claim that it is affecting crop and livestock production, and indigenous species. This claim may be due to lack of awareness of the ways to use it to improve their socioeconomic and biophysical environment. There for it invites, future studies to adjust the positive and negative impacts of the species to control and eradicate if possible from where it is undesirable and to derive the services it gives where it is desirable when there is no option.

\section{Conclusions and Recommendations}

The results of the study has indicated that the invasive species Lantana camara has impact on indigenous species composition through decreasing species diversity. Disturbance in the form of herbivory was found to be the major factor facilitating the invasion and encroachment of Lantana.

Decrease in livestock market and crop production through encroachment on grazing and farmlands is found to be the negative socioeconomic impact. While reclaiming degraded lands, preventing erosion prone areas from erosion, increasing soil fertility and use as a live fence were found the positive socio-economic impacts.

Based on the results the following recommendations are forwarded:

- The society should be awared not to use the land for grazing or browsing more than its carrying capacity, as disturbance in the form of herbivory is found to be the major factor facilitating invasion and encroachment of the species.

- Provision of training on how to use the species to improve biophysical and socio economic environment. For example; planting it on eroded areas for rehabilitation of the areas, and in erosion prone areas to prevent erosion and to use it for live fence around farm steads and home gardens.

- Removing it before seed production for seed production is the major means of encroachment to uninvaded areas.

- Planting those species of plants, which can outcompete it. 
- Determination of the threshold level for decline in biodiversity and the identification of "management barriers" to invasion.

\section{References}

Anonymous (2003).Invasion Rates and Risks. Online: [www.aliens.csir.co.za]

Anonymous (2003). Guide lines for Mapping Invading Plants. Online: [http://www. Fred.esir.co.za.20/01/2003.

Barnes, B. V. and Hopkins, S.B. (1997).Forest Ecology. Binggeli P. and Desalegn Dessisa (2002). Lantana camara.

The Invasive that Threaten to Drive People out of their Land. Newsletter of the Ethiopian Wildlife and Natural History Society.

Binggeli P .and Desalegn Dessisa (2002). Lantana camara. The Invasive that Threaten to Drive People out of their Land. Newsletter of the Ethiopian Wildlife and Natural History Society.

Binggeli, P., Hall, J.B., and Healy, J.R. (1998). An Overview of Invasive Woody Plants in the Tropics. School of Agricultural and Forest Science Publication No.13.University of Wales, Bangor.

Cronk, Q. C.B., and Fuller, J.L. (1995).Plant Invaders, London: Chap man and Hall.

Crawley, M.J. (ed.) (1997).Plant Ecology 2nd edn. Black well Science, Cambridge, U.K.

D'Antonio, C.M. (2000). Fire, Plant Invasions and Global Changes. In Mooney, H.A. and H.A. Hobbs (eds). Invasive Species in a Changing World. Island Press. Washington D.C.

Dessalegn Dessisa and Binggeli, P. (2003).Ethiopian Plants. Online: [http://members.lycos.co.uk].

EARO. (1996). IAS (invasive alien species). Removing the Barriers to Invasive Species Management.

Online[http://www.undp.org/gef/index.htm/.

Gentle, C.B., and Duggin, J.A. (1997). Lantana camara Invasions in Dry Rain Forest Open Forest Ecotones. The Role of Disturbances Associated with Fire and Cattle Grazing. Australian Journal of Ecology 22; 298-306.

Hailu Shferaw. (2002). Some Biological Characteristics that Foster the Invasion of Prosopis juliflora (sw.) DC.at Middle Awash Rift Valley Area, Northeastern Ethiopia. Maters Thesis, Addis Ababa University.

Hobbs, R.J. (1989). The Nature and Effects of Disturbance Relative to Invasions. A Global Perspective. In Drake, J.A., Mooney, K.A, DiCastri, F. (eds). Wiley. Chichester, UK.pp.389-405.

Hobbs, R.J. (2000). Land Use Changes and Invasions. In Mooney, H.A. and H.A. Hobbs (eds).Invasive Species in a Changing World. Island press. Washington D.C.

Kassahun Zewdie (1999). Prosopis (Prosopis juliflora) in Ethiopia (Fassil Reda, Tanner, D.G., (eds.) Arem 5, 96102. Ethiopian Weed Science Society, Addis Ababa, Ethiopia.

Katerina, B; Bohumil, M and Ivana, K. (2004). How Does Reynoutria Invasion Fit the Various Theories of Invisibility? Journal of Vegetation Science 15:495- 504.IAVS: Opulus Press Uppsala.

Kumelachew Yeshitela and Taye Bekele (2003). The Woody Species Composition and Structure of MashaAnderacha

Forest, South western Ethiopia, Ethiop.J.Biol.Sc.2 (1): 31-48.

Mack. M.C. and D’Antonio. C.M. (1998). Impacts of Biological Invasions on Disturbance Regimes.Treevol.13, no5, pp195-198.

McNeely, J.A. (2000). The Future of Alien Invasive Species: Changing Social Views. In Mooney, H.A.and Hobbs,

H.A. (eds). Invasive Species in a Changing World. Island Press. Washington D.C.

McNeely, J.A. (2001). The Great Reshuffling. Human Dimensions of Invasive Alien Species. IUCN, Gland and Cambridge, 242pp.

Morton, J.F. (1994).Lantana, or a Red Sage (Lantana camera L., (Verbeneceae), notorious weed and Popular Garden Flower; Some Cases of Poisoning in Florida. Economic Botany48:259-270.

Pimentel, D., Lach, L., Zuniga, R. and Morrison, D. (2000). Environmental and Economic Costs of Nonindigenous Species in the United States. Bioscience 50, 53-56.

Roxana, A and Msnuel, M.J. (2003).Species Composition and Invasion in NW Argentinian Secondary Forests: Effects of Land use History, Environment and Landscape. Journal of Vegetation Science 14:195-204.IAVS: Upulus Press Uppsala.

Segretain, B; Helene and Arnauld, E. (2004). Experiments on Growth Interactions Between two Invasive Macrophyte Species. Journal of Vegetation Science15:109- 114.IAVS: Opulus Press Uppsala.

Sharma, O.P., Makkar, H.P.S.and Dawra, R.K. (1988). A Review of the Noxious Plant Lantana camara.Toxicon26; 957-987.

Swarbrick, J.J., Wilson, B.W., and Hannan, J M.A. (1995). The Biology of Australian Weeds.25.Lantana camara L.

Plant Protection Quarterly 10:82-95.

Thakur, M.L., Ahmad, M and Thakur, R.K. (1992), Lantana Weed (Lantana camara Var. aculeate linn). And its Possible Management through Natural Insect Pest in India. Indian Forester 118(7):466-485.

UNEP, (2000b). Decisions Adopted by the Conference of the Parties to the Convention on Biological Diversity at Its Fifth Meeting, UNEP, Nairobi. 
UNEP, (2000c). Policy Recommendation: Alien Species that Threaten Ecosystem.UNEP, Nairobi.

Wilkinson, D.M (1999). The Disturbance History of Intermediate Disturbance. Oikos 84(1) pp.145-147.

Williamson, M. (1996).Biological Invasions. Chap man and Hall, London, 244pp

Wittenberg, R. and. Cock, M.J.W. (2000). Invasive Alien Species: a Toolkit of Best Prevention and Management Practices. Global Invasive Species Programmme, CAB International, Wallingford, Oxon, UK. 